\title{
Serviço Social e questão agrária: um debate necessário ao fortalecimento da direção crítica do projeto ético-político- profissional
}

Social work and agrarian question: a considerable debate to the strengthening of the critical direction of the ethical-political-professional project

\author{
Raquel Santos Sant'Ana* \\ Gabriela Abrahão Masson**
}

\section{Resumo:}

Este texto problematiza o surgimento do Serviço Social como profissão atrelada ao modo de produção capitalista em seu estágio monopólico e, discute o objeto de intervenção profissional, a questão social, como inerente à produção e reprodução desta sociabilidade calcada na lei geral de acumulação do capital. A partir da realidade brasileira aponta a construção histórica da direção crítica do Projeto Ético Político do Serviço Social, bem como a questão agrária como particularidade da questão social cujas manifestações se expressam pelo embate e contradições advindos do atual modelo de desenvolvimento agrário, o qual prioriza o agronegócio em detrimento da agricultura camponesa e/ou de outros sujeitos políticos que lutam por terra ou trabalho em meio rural. Finaliza a reflexão apontando à necessidade da apreensão da questão agrária no cotidiano do trabalho profissional do assistente social por meio de suas diversas manifestações; destaca que esse debate é parte da qualificação necessária para a apreensão da realidade na perspectiva de totalidade e, de uma formação crítica alinhada ao Projeto Ético Político profissional do Serviço Social e sua direção crítica e dialética.

Palavras-chave: Serviço social. Questão social. Questão agrária.

\begin{abstract}
:
This text problematizes the beginning of Social Work as a profession linked to the capitalist mode of production in its monopolist phase. It also discusses the object of professional intervention, the social question, as inherent to the production and reproduction of this sociability rooted in the general law of capital accumulation. From a Brazilian perspective, this work shows the historical construction of the political direction of social work's Ethical Political Project, as well as the agrarian question as a social question particularity, whose manifestations are expressed by the crash and contradictions emerged from the current model of agrarian development. This model prioritizes the agribusiness over peasant agriculture and/or other political subjects who fight for lands or work in the rural areas. The present work ends the reflection showing the need to the introduction of the agrarian question into the everyday professional work of the social worker through its diverse manifestations; it is pointed out that this debate is part of the necessary qualification to the apprehension of the reality from a holistic perspective and from a critical construction aligned to the social work professional Ethical Political Project and its critical and dialectical direction.
\end{abstract}

Keywords: Social work. Social question. Agrarian question.

\footnotetext{
* Doutora e livre docente em Serviço Social. Professora adjunta da Faculdade de Ciências Humanas e Sociais de da Universidade Estadual Paulista "Júlio de Mesquita Filho", Campus de Franca/SP. E-mail: raquelssfranca@yahoo.com.br

** Assistente Social, Profa. Dra. do Departamento de Serviço Social da Universidade Federal do Triângulo Mineiro (UFTM), Uberaba/MG.
} 


\section{Introdução}

O Serviço Social completou, em 2018, 82 anos de existência no Brasil. Uma profissão que surge para atender às demandas do capital e do Estado, mas que nesse curto período promove uma reviravolta político-ideológica que o leva construir coletivamente uma direção social de cunho crítico e comprometido com a luta dos/das trabalhadores/as.

Diversos elementos contribuíram para o Serviço Social brasileiro construir essa trajetória, mas nesta concepção, dois em especial foram fundamentais: pensar o trabalho e a formação profissional de maneira indissociada, enquanto unidade dialética, conseguir reunir e mobilizar as entidades representativas da categoria e o movimento estudantil de Serviço Social para ações conjuntas e sintonizadas. Isso deu força para essa direção política assumida pela profissão nos últimos 40 anos e, que foi conveniente chamar de Projeto Ético Político Profissional (PEP).

Nesta publicação, que é parte das comemorações dos 20 anos do periódico Serviço Social em Revista da Universidade Estadual de Londrina, será discutido a construção histórica dessa direção ético-política realizada pelo Serviço Social e, o entendimento que a profissão tem da questão social a partir da teoria marxiana, principal referencial teórico que fundamenta o PEP, em uma direção crítica dialética. Em seguida, foi problematizado a questão agrária, enquanto particularidade da questão social no Brasil, atinente à formação do modo de produção capitalista brasileiro e, como essa problemática incide na formação e no trabalho profissional.

\section{O Surgimento do Serviço Social e Direcionamento Ético Político Atual}

O primeiro curso superior em Serviço Social foi criado em 1936 na Pontifícia Universidade Católica de São Paulo (PUC). Segundo lamamoto e Carvalho (2014), o Serviço Social em suas origens, estava intimamente vinculado às iniciativas da Igreja articuladas aos movimentos de Ação Social e Ação Católica, portanto de base confessional e com cariz ideológico fundado na doutrina social da Igreja.

As análises que problematizam o surgimento da profissão à luz da teoria-socialcrítica realizadas por Paulo Netto (2005), lamamoto e Carvalho (2014), lamamoto (2008) e Siqueira da Silva (2010) evidenciam que sua "gênese" não se deu apenas como evolução das práticas caritativas ou assistenciais, mas, sobretudo, como resultante da própria dinâmica do capitalismo monopolista no final do século XIX e início do século XX. 
Segundo Santos (2012) a partir da década de 1930 foi consolidado o processo de substituição de importações de produtos manufaturados da indústria nacional, portanto, a chamada industrialização restringida tomava forma no cenário brasileiro; a consolidação do capitalismo industrial foi a alavanca para o desenvolvimento no Brasil, ainda que em consonância com os interesses da burguesia agrária. Assim, é a partir desta década, que é consolidada a integração do Brasil ao capitalismo internacional, não eliminado o seu caráter agroexportador fundado no latifúndio monocultor, aliado a um significativo crescimento da produção tanto agrícola, quanto industrial para o mercado interno.

Esta realidade consubstanciou à formação do mercado de trabalho brasileiro e a instituição progressiva do trabalho assalariado como regime de trabalho no país. Em 1943 é aprovada a Consolidação das Leis do Trabalho, fruto de diversas lutas sociais e greves que eclodiram por todo o território brasileiro. No entanto, a incorporação da força de trabalho neste mercado foi totalmente desigual e excludente, uma vez que pouco incorporou a massa de trabalhadores/as libertos do modo de produção escravocrata. A estratégia adotada ainda na República Velha e intensificada a partir da década de 1930 foi a substituição da força de trabalho dos negros escravizados pela dos imigrantes que ancoraram no Brasil, descartados pelo capitalismo industrial no final do século XIX na Europa. Segundo Stédile (2012, p. 27): "[...] a Coroa atraiu para o Brasil, no período de 1875-1914, mais de 1,6 milhões de camponeses pobres da Europa", que aqui se estabeleceram em sistema de colonato.

No Brasil, é neste contexto que ocorre o crescente aproveitamento e cooptação do Serviço Social pelo aparato do Estado e pelo empresariado que, por sua vez, atribuem progressivamente novas determinações à sua legitimação e institucionalização. Nos termos de lamamoto e Carvalho (2014, p.83): “O Assistente Social passa a receber um mandato diretamente das classes dominantes para atuar junto às classes trabalhadoras."

Assim, o Serviço Social é parte constituinte de um complexo processo comprometido com a formulação de inúmeras estratégias utilizadas para maximizar e intensificar a acumulação do capital, modernizando e profissionalizando a gestão do pauperismo e das contradições da relação capital/ trabalho.

A formação e trabalho do Assistente Social no início da profissão foi travejada por concepções filosóficas abancadas no neotomismo e no positivismo, que ora reiteravam à prática profissional o caráter de ajuda e benevolência, ora à moralização da vida dos pobres e, o consequente ajustamento dos indivíduos sociais. Netto $(1996$, p. 66) destaca, 
[...] a constituição da profissão seria a resultante de um processo cumulativo, cujo ponto de arranque estaria na "organização" da filantropia e cuja culminação se localizaria na gradual incorporação, pelas atividades filantrópicas já "organizadas" de parâmetros técnicos científicos e no afinamento de um instrumental operativo de natureza técnica [...].

A dinâmica do Serviço Social é impensável sem a análise sócio-histórica da realidade brasileira que determinou as demandas sociais partir da década de 1930, bem como o tratamento que a profissão dispensou a tais demandas. Com o aprofundamento dos antagonismos de classe, ao Assistente Social foi atribuído o papel de contribuir com a reprodução do controle da ideologia dominante sobre os trabalhadorxs com o apaziguamento das contradições inerentes às relações sociais vigentes. Conforme evidencia Siqueira da Silva (2010, p. 57),

\begin{abstract}
Ao mesmo tempo em que a "questão social" se aprofunda trazendo com ela os traumas sociais de uma sociedade colonial, escravocrata, patriarcal, pré-capitalista e com desenvolvimento burguês hipertardio (como uma necessária mescla entre moderno e arcaico), o Estado crescentemente assume tarefas vinculadas ao disciplinamento, à reprodução-preparação da força de trabalho e à manutenção e recuperação-reparação da capacidade para o trabalho.
\end{abstract}

É essa contradição capital/trabalho que o Serviço Social irá denominar de "questão social", já na década de 1980, amparado no debate trazido pela tradição marxista. As reflexões sobre gênese do que denominamos de questão social são impensáveis sem as análises de Marx (2009), mais especificamente o Capítulo XXIII de O Capital: A Lei Geral da Acumulação Capitalista.

Segundo Marx (2009), a partir do século XVIII o pauperismo é produto intrínseco e latente da sociabilidade regida pelo capital, sua produção e sua necessidade comportam a existência da superpopulação relativa e do exército industrial de reserva. Ambos, constituem condição para a produção e reprodução do modo de produção capitalista, do desenvolvimento, concentração e centralização da riqueza socialmente produzida e privadamente apropriada.

Sendo assim, na medida em que os trabalhadorxs explicitam suas condições de trabalho, expressas por jornadas ininterruptas e extenuantes, que já não são mais capazes de suprir suas necessidades sociais, o pauperismo também se torna cada vez mais latente e evidente no cenário político dos grandes centros europeus do século XVIII. Conforme MarX (2009, p. 747-748) destaca: 
O pauperismo constitui o asilo dos inválidos do exército ativo dos trabalhadores e o peso morto do exército industrial de reserva. Sua produção e sua necessidade se compreendem na produção e na necessidade da superpopulação relativa, e ambos constituem condição de existência da produção capitalista e do desenvolvimento da riqueza. O pauperismo faz parte das despesas extras da produção capitalista, mas o capital arranja sempre um meio de transferi-las para a classe trabalhadora e para a classe média inferior.

Portanto, o surgimento do pauperismo é para Marx uma realidade concreta atrelada à lei geral de acumulação capitalista, já que a partir deste modo de produção a pobreza é mundialmente produzida e reproduzida a partir da exploração da força de trabalho que produz mais-valia para uma determinada classe social que possui/ detém os meios de produção.

Segundo lamamoto (2001) e Santos (2012) a nominação "questão social" foi cunhada por volta de 1830 e embora, Marx nunca não tenha usado essa expressão, a problemática que ela abarca se encontra no centro de suas análises. As autoras destacam que a questão social é intrínseca à sociabilidade regida pelo capital, portanto. tem sua existência fundada no modo de produção capitalista bem como na necessidade de políticas sociais públicas que são as estratégias assumidas pelo Estado para apaziguar a organização e mobilização da classe trabalhadora na denúncia e recusa às condições de vida e trabalho imposto.

A apropriação marxiana da questão social como as contradições advindas da relação contraditória capital/trabalho, se por um lado coloca a impossibilidade de sua superação nessa sociabilidade, por outro evidencia que o modo de produção capitalista se reconfigura e vai trazendo novas características e particularidades a esse confronto e suas resultantes. Embora suas manifestações imediatas se expressem como pobreza, desigualdade, violência ou indigência, a maneira como estas vão se apresentando se dá a partir dos diversos rebatimentos das relações estabelecidas entre as classes e segmentos de classe.

A dinâmica política é intrínseca à compreensão da questão social, bem como de suas manifestações, pois é por meio de resistência e luta social que a classe trabalhadora historicamente se organizou e organiza para trazê-la à cena política. Nesta direção, Netto (1996, p. 90) elucida a questão social como: "[...] o conjunto de problemas econômicos, sociais, políticos, culturais, e ideológicos que cerca a emersão da classe operária como sujeito sócio-político no marco da sociedade burguesa." 
Historicamente, surgiram justificativas divinas e moralistas que ratificavam as desigualdades sociais por meio da vontade de Deus; ora eram tratadas com práticas criminalizadoras, como objeto de repressão e intervenção policial. Ou ainda, com políticas pouco eficientes que na verdade não combatem de maneira estrutural os determinantes da questão social, mas apenas atuam pontualmente nas suas manifestações/ consequências, já que sua supressão no capitalismo é intangível. A esse respeito, Mota (2009, p.49, grifo da autora):

A rigor não existem - do ponto de vista histórico, político e teórico - muitas alternativas para pensar a natureza do enfrentamento da questão social. Pode-se, de fato, falar apenas de duas tendências gerais: sua administração no interior da ordem burguesa - demarcada pela implementação de reformas sociais e morais, tanto mais "eficientes" quanto mais ancoradas tecnicamente - ou a sua superação como uma prática que transforma não a questão social em si, mas a ordem social que a determina.

Ou na reflexão de Siqueira da Silva (2010, p. 199),

O Serviço Social ocupou, desde sua origem, uma posição de "gerente" das tensões - imediatamente manifestada nos indivíduos sociais - advindas da contradição estrutural entre capital e trabalho. A "questão social" e suas particularidades expressões sempre desafiaram o cotidiano profissional dos assistentes sociais, independente de ela ser reconhecida ou não como tal, por eles próprios. Não é possível, portanto, como já foi intensamente analisado, negar o caráter funcional das políticas sociais (situadas, quando muito, em níveis pontuais da emancipação política) e dos diversos tipos de intervenção profissional que, a partir delas, foram se configurando.

Portanto, convivemos nesta sociabilidade com as tentativas de controle da questão social, sendo possível visualizar sua gestão por meio de medidas estatais que de alguma forma responderam e respondem aos interesses e necessidades do trabalhador. No entanto, até o fim do século XIX tais respostas foram tímidas e parciais devido às características do desenvolvimento do modo de produção capitalista assumido nesse país e, ao predomínio dos princípios liberais assumidos pelo Estado capitalista.

O surgimento das políticas sociais aconteceu através de um processo gradual e diferenciado entre os países, atrelado aos movimentos de organização e pressão da classe trabalhadora e, sobretudo, ao interesse do Estado Moderno conforme Netto (2008, p.23) destaca: "[...] nada expressa melhor o papel do Estado como preservador dos interesses gerais do capital do que as políticas sociais". 
Historicamente, as políticas sociais no Brasil para Netto $(1996,2008)$ são estratégias, governamentais ou não, para conter e sanar diversas manifestações da questão social acirradas pelo embate entre capital e trabalho nos marcos do capitalismo monopolista. Mas, acima de tudo, como fruto de lutas e conquistas da classe trabalhadora em prol da satisfação de suas necessidades sociais.

Ainda que as políticas sociais não possam eliminar a questão social pelos motivos expostos, num cenário de controle "sociometabólico" intensivo do capital sobre as necessidades sociais da classe trabalhadora, algumas delas vão se tornando imprescindíveis para a garantia da satisfação das chamadas necessidades naturais; nos termos de Marx (2009): indispensáveis para a manutenção da condição humana, como: comer, vestir, morar e se proteger do frio.

Na década de 1960, frente a um cenário de expansão do capitalismo mundial e imposição de um estilo de desenvolvimento excludente, dependente e subordinado à América Latina, cria-se um clima de agitação política que vai trazer rebatimentos diretos sobre o Serviço Social. É inaugurado um processo de questionamento das bases do Serviço Social tradicional. Inicia-se o debate e crítica, mediante um amplo movimento de revisão conhecido como "Reconceitualização do Serviço Social", que ocorreu em toda a América Latina. Um processo de renovação estudado profundamente por Netto (2005, p. 131):

\footnotetext{
Entendemos por renovação o conjunto de características novas, que no marco das constrições da autocracia burguesa, o Serviço Social articulou a base do rearranjo de suas tradições e da assunção de do contributo de tendência do pensamento social contemporâneo, procurando investir-se como instituição de natureza profissional dotada de legitimação prática, através de respostas e demandas sociais e de sua sistematização e de validação teórica, mediante a remissão às teorias e disciplinas sociais.
}

Netto (2005, p.128) aponta que é incontestável que o Serviço Social brasileiro, até a primeira metade da década de 1960, não apresentava polêmicas de relevo, somente mostrava uma relativa homogeneidade nas suas projeções interventivas, pois "sinalizava uma formal assepsia de participação político-partidária carência de uma elaboração teórica significativa." 
No Brasil, o chamado Movimento de Reconceituação ${ }^{1}$, parte integrante do processo internacional de erosão do Serviço Social tradicional na América Latina, incidiu nos níveis ético, teórico, metodológico, operativo e político.

Segundo Netto (2005) tal movimento foi configurado por três vertentes, ou perspectivas que ainda que não tenhamos condições de reproduzir aqui o debate, é importante mencionar: 1- perspectiva modernizadora: fundada sob bases teóricas positivistas, cuja ênfase era modernizar e integrar a profissão ao projeto de desenvolvimento em curso e, que teve prevalência a partir de meados dos anos setenta; 2reatualização do conservadorismo: que foi assim denominada por Netto, pois ainda que reclamasse a inspiração fenomenológica, na realidade recuperava aquilo que havia de mais tradicional no Serviço Social com ênfase para o atendimento de casos e ênfase psicologizante; 3- a perspectiva intenção de ruptura: na primeira metade dos anos 1980, se inicia um processo mais fundo de crítica e ruptura com o Serviço Social tradicional. Conforme destaca Netto (2005, p. 159): “Ao contrário das anteriores, esta possui como substrato nuclear uma crítica sistemática ao desempenho 'tradicional' e aos seus suportes teóricos, metodológicos e ideológicos²." Daí, inclusive sua dificuldade de efetivação na profissão durante os anos mais duros do regime militar (1969 a 1974), afinal essa corrente negava a ordem social posta.

Um dos elementos constitutivos do processo de renovação foi a emergência, a partir da década de 1970, de um significativo caldo de elaborações teórico-metodológicas referidas à profissão nos âmbitos acadêmicos e universitários. Nos termos Netto (2005) a "massa crítica" começara a ser gestada. Esse processo, no entanto, foi feito com obras do marxismo vulgar travejado de ecletismos teóricos, o que trouxe inúmeras dificuldades para a efetivação dessa matriz no âmbito da profissão além da própria conjuntura política do período.

Em 1972 em Belo Horizonte, ditadura militar, ocorre a experiência de trabalho inspirada na tradição marxista e que ficou conhecida como o "Método BH". Porém em 1979, na cidade de São Paulo, que as/os assistentes sociais, lideradas/os principalmente pelas

\footnotetext{
${ }^{1}$ Não será possível no espaço desse texto discutir a renovação do Serviço Social brasileiro, mas a esse respeito existem publicações que permitem o entendimento de todo o processo. A esse respeito CF: Paulo Neto (2005)

2 Esta vertente emergiu da estrutura universitária brasileira com formulação inicial na Escola de Serviço Social da Universidade Católica de MG.
} 
entidades sindicais da profissão, mudam a direção política do III Congresso Brasileiro de Assistentes Sociais (CBAS), conhecido como o "Congresso da Virada".

Desta forma, a partir da década de 1980, com o considerável acúmulo sóciohistórico da profissão, ocorre um adensamento teórico-metodológico, ético-político e técnico-operativo, resultantes do arcabouço já acumulado durante o Movimento de Reconceituação; um processo que incluiu a aproximação e aprofundamento teórico com as Ciências Sociais, o envolvimento da categoria profissional com a conjuntura política brasileira, mas que foi resultante, também, do aumento do número de profissionais, da criação dos primeiros programas de pós-graduação e, ampliação dos espaços de trabalho.

A conjuntura política do início doa anos de 1980 vai possibilitar ao Serviço Social o engajamento nas lutas sociais, a aproximação com os movimentos sociais e com as lutas da classe trabalhadora. Foi um período que permitiu uma interlocução mais ampliada com a tradição marxista e marxiana, o que segundo Netto (2006) possibilitou a compreensão do significado social da profissão e do objeto de intervenção profissional, como também um adensamento na produção científica dos assistentes sociais.

Desde o período de redemocratização até os dias atuais a profissão tem movido esforços no sentido de fazer avançar essa direção crítica assumida pelo Serviço Social. Na década de 1980, logo após o Congresso da Virada, um dos maiores investimentos da profissão foi voltado para a formação profissional. Em 1982, foi aprovado um novo currículo com matriz crítica, que superava a perspectiva do currículo anterior cuja estrutura para o estudo do trabalho profissional se dava a partir do atendimento de caso, grupo e comunidade. Este novo currículo se apoiava no debate sobre teoria, método e história do Serviço Social e avançava do ponto teórico-político. Em 1996, a partir de uma construção coletiva promovida pela então Associação Brasileira de Ensino em Serviço Social ${ }^{3}$ (ABESS) foi aprovada uma nova proposta de formação profissional para os cursos de Serviço Social.

Ainda que não haja espaço para esse debate nesse texto, é importante frisar a importância esse documento intitulado "Diretrizes Gerais para o curso de Serviço Social" que é, até a presente data, a referência para a formação das Unidades de Ensino filiadas a ABEPSS ${ }^{4}$. Nele a direção crítica é aprofundada e a formação é trabalhada a partir de Núcleos

\footnotetext{
${ }^{3}$ Hoje Associação de Ensino e Pesquisa em Serviço Social (ABEPSS).

${ }^{4}$ Esse documento adaptado por uma comissão de especialistas de serviços social foi enviado ao MEC na época da aprovação das diretrizes curriculares para os cursos de nível superior no Brasil. O MEC incorporou a organização da formação por núcleos, mas retirou das diretrizes efetivamente lançadas oficialmente, 0 direcionamento ético-político do documento da ABEPSS.
} 
de Fundamentação: o núcleo de fundamentos teórico-metodológicos da vida social; o núcleo de fundamentos da particularidade da formação sócio-histórica da sociedade brasileira e, o Núcleo de fundamentos do trabalho profissional. Os conteúdos desses Núcleos são indissociáveis, pois articulados e voltados para a apreensão da realidade na perspectiva de totalidade.

Outro elemento desse acúmulo crítico da profissão, importante a ser destacado, foi o grande salto do debate da ética que ocorreu com a aprovação do Código de Ética de 1986, em que pela primeira vez o Serviço Social assume uma perspectiva histórica no debate da temática. Em 1996, é aprovado um novo código pelo Conselho Federal de Serviço Social que mantém a perspectiva crítica e histórica da Ética profissional prevista no de 1986, mas que avança superando as lacunas do anterior.

Essa organização e mobilização política da categoria profissional em torno de suas entidades representativas: Conselho Federal de Serviço Social (CFESS); Conselhos Regionais de Serviço Social (CRESS)s, Associação Brasileira de Ensino e Pesquisa em Serviço Social (ABEPSS), e Executiva Nacional dos Estudantes de Serviço Social (ENESSO) foram e são fundamentais para o atual direcionamento teórico-metodológico e ético-político da profissão. Outro marco legal desse processo coletivo é importante ser mencionado como a revisão da Lei de Regulamentação da Profissão, encaminhada ao congresso em 1986 e aprovada em 1993 por meio da Lei Federal no 8.662. As publicações de Marilda Vilela lamamoto, Raul de Carvalho e José Paulo Netto que fizeram interlocuções profícuas com a teoria-social-crítica.

São 40 anos de debate com a categoria profissional de maneira a refletir e construir a "massa crítica" para o entendimento de uma profissão que é chamada para atuar no sentido de amenizar o conflito de classe resultante dessa sociabilidade, mas que constrói outra direção ético-política: a defesa da classe trabalhadora.

O que convenciona-se, hoje chamar Projeto Ético Político do Serviço Social, é resultante deste processo e que está em permanente construção e reconstrução dialética. Suas bases teórico-metodológicas, ético-políticas e técnico-operativas, avigoradas na teoriasocial-crítica, se constituem em um horizonte para a formação e o trabalho profissional na atualidade e expressam o compromisso da profissão com a classe trabalhadora e com a justiça social. Esta construção também deve ser tecida cotidianamente junto à organização, mobilização, luta e resistência dos movimentos sociais e organizações de representação dos trabalhadores, tendo em vista o horizonte anticapitalista e emancipatório que o PEP expressa. 
A tradição teórica inspirada em Marx à teoria-social-crítica possibilita entender as particularidades imprescindíveis para compreensão do significado social da profissão, bem como as que fundam o ser social na ordem burguesa do capital, os sujeitos sociais com os quais trabalhamos no cotidiano profissional. Desta forma, também viabiliza a categoria profissional a construção de um ethos profissional comprometido com os princípios que fundam a profissão na contemporaneidade, que versam sobre:

\begin{abstract}
O reconhecimento da liberdade como valor ético central e das demandas políticas a ela inerentes - autonomia, emancipação e plena expansão dos indivíduos sociais; Defesa intransigente dos direitos humanos e recusa do arbítrio e do autoritarismo; Ampliação e consolidação da cidadania, considerada tarefa primordial de toda sociedade, com vistas à garantia dos direitos civis, sociais e políticos das classes trabalhadoras; Defesa do aprofundamento da democracia, enquanto socialização da participação política e da riqueza socialmente produzida; Posicionamento em favor da equidade e justiça social, que assegure universalidade de acesso aos bens e serviços relativos aos programas e políticas sociais, bem como sua gestão democrática; Empenho na eliminação de todas as formas de preconceito, incentivando o respeito à diversidade, à participação de grupos socialmente discriminados e à discussão das diferenças; Garantia do pluralismo, através do respeito às correntes profissionais democráticas existentes e suas expressões teóricas, e compromisso com o constante aprimoramento intelectual; Opção por um projeto profissional vinculado ao processo de construção de uma nova ordem societária, sem dominação-exploração de classe, etnia e gênero; Articulação com os movimentos de outras categorias profissionais que partilhem dos princípios deste Código e com a luta geral dos trabalhadores; Compromisso com a qualidade dos serviços prestados à população e com o aprimoramento intelectual, na perspectiva da competência profissional; Exercício do Serviço Social sem ser discriminado, nem discriminar, por questões de inserção de classe social, gênero, etnia, religião, nacionalidade, opção sexual, idade e condição física (CFESS, 2008, p. 42-43).
\end{abstract}

É evidente que este é um processo tenso e contraditório, especialmente em conjunturas adversas como a atual. As dificuldades de manter essa direção crítica são permanentemente revigoradas seja pelos desafios próprios da formação profissional cada vez mais dilacerada, por políticas públicas seletivas, focalizadas, privatizadas e financeirizadas; por condições de trabalho extremamente precarizadas, com intensificação e extensão das jornadas, flexibilização da produção e das relações de trabalho, vínculos informais; no âmbito da sociabilidade o avanço do conservadorismo e do reacionarismo, que se evidenciam por meio do machismo, da LGBTfobia e racismo.

Enfim, é no conjunto dos embates dessa sociabilidade que a profissão se coloca para lutar por uma direção crítica dialética comprometida com a luta dos trabalhadores. 


\section{A Questão Agrária e o Serviço Social: Alguns Apontamentos}

Conforme já discutido, a formação e atuação profissional do/a Assistente Social é travejada na luta contra o pauperismo, cujo fundamento é a sociedade do capital e suas relações iníquas de exploração e opressão. As resultantes desse processo desencadeiam no que convencionamos chamar de questão social, historicamente concebida e entendida como objeto de intervenção do Assistente Social em seus espaços sócio-ocupacionais.

No contexto do capitalismo brasileiro - tardio - a questão social está estritamente atrelada ao surgimento e agravamento da questão agrária, que se constitui uma das suas particularidades, conforme afirma Sant'Ana (2012, p.14):

\footnotetext{
Uma das particularidades da questão social é a questão agrária. Esta é resultado dos embates estabelecidos devido à posse da terra ou às relações de trabalho em meio rural; no atual modelo de desenvolvimento agrário uma de suas principais expressões ocorre pelo embate na relação capital/ trabalho que ocorre no campo e na cidade, mas que é decorrência do avanço das relações capitalistas no campo.
}

Diante do atual modelo de desenvolvimento agrário apontado por Sant'Ana (2012), diversas manifestações da questão social são engendradas em todo o território nacional em decorrência do desenvolvimento massivo do agronegócio, como forma predominante de relações econômicas na agricultura.

Alguns elementos da questão urbana também estão diretamente imbrincados com a questão agrária como é o caso do ligeiro processo de urbanização ocorrido entre as décadas de 1960 a 1980, produto da chamada "modernização no campo". Prado Júnior (2000) alertou sobre este processo: na medida em que o monopólio de terras está concentrado nas mãos de uma minoria de grandes proprietários, a massa trabalhadora seria impelida a buscar trabalho, e diante dos verdadeiros exílios que vivenciavam e vivenciam nas periferias, as ocupações urbanas configuraram e ainda se configuram como uma alternativa.

Segundo Diniz (2014), o Brasil apresenta crescimento das cidades em que $80 \%$ da população concentra-se nas áreas urbanas e $40 \%$ nas áreas metropolitanas. Esta conjuntura é a herança resultante da urbanização intensiva ocorrida entre os anos de 1940 a 2000, fruto do processo de êxodo rural, uma das consequências da modernização conservadora. A população urbana era de $23,3 \%$ e cresceu para $81,2 \%$. Isso gerou um enorme déficit habitacional, tanto na cidade quanto no campo, estimado em 7,9 milhões de unidades habitacionais, sem contar o número significativo de assentamentos rurais precários, nos quais se alojam cerca de 3,2 milhões de famílias (DINIZ, 2014). 
Portanto, com o surgimento e aprofundamento da questão agrária observa-se também o surgimento e agravamento da questão urbana, ambas resultantes da sociabilidade do capital que aparta o trabalhador dos meios de trabalho e estabelece relações de exploração, que no caso do Brasil são pautadas em um processo de superexploração e consequentemente geram a questão social no campo e na cidade (MARINI, 2011).

Os determinantes da questão agrária são resultantes do desenvolvimento das relações capitalistas no campo e/ou do cerco do capital sobre os territórios. No caso do Brasil, a manutenção de uma estrutura agrária extremamente concentrada foi possível por vários motivos, dentre eles a dimensão continental do país que permitiu que a terra pudesse ser utilizada como reserva de valor pelos latifundiários, sem com isso afetar as atividades capitalistas, cujos empresários do setor puderam assumir tanto a condição de latifundiários quanto de empresários agrícolas, sem ter que pagar renda da terra.

Mecanismos legais, políticos e econômicos foram sendo historicamente construídos e legitimados pelo Estado de maneira a viabilizar esse pacto das elites agrárias com o capital, sempre numa perspectiva excludente e desestabilizadora da agricultura e da população camponesa. Ainda que não haja espaço para a retomada histórica desse processo neste texto, é importante mencionar que durante os anos da última ditadura militar ocorrida nesse país (1964 a 1984), esse processo se efetiva de maneira mais ampliada com a política implantada que ficou conhecida como "Revolução Verde". Na realidade, foram sendo implantadas uma série de políticas agrícolas justificadas como necessárias para a superação do atraso na agricultura, mas que, na realidade, foram a opção de modernização do campo da classe dominante e do Estado.

Os impactos da modernização ${ }^{5}$ proposta tiveram rebatimentos sociais e ambientais muito graves. As expulsões, mortes, a exploração, o desenraizamento das populações tradicionais e camponesas foram a marcas desse processo. O aumento da base técnica da agricultura ocorreu vinculado a uma proposta de desenvolvimento a partir da lógica capitalista, que para a natureza é absolutamente irracional, pois, contraria em essência a sua forma de funcionar. Ou seja: a proposta de modernização do campo se deu a partir de um modelo de produção voltado para a monocultura agroexportadora cultivada em grandes extensões de terra, que utiliza equipamentos pesados que impactam o solo e a quantidade

\footnotetext{
${ }^{5}$ A modernização agrícola foi bastante discutida na literatura sobre questão agrária e foi chamada por alguns autores como "conservadora" (SILVA, 1998).
} 
de agrotóxico. Essa forma de produzir contraria a forma de funcionar da natureza, cujo equilíbrio exige necessariamente a biodiversidade. Por isso a necessidade do modelo implantado ser campeão na utilização de agrotóxicos, afinal é preciso controlar artificialmente o desiquilíbrio que essa forma de produzir gera.

Isso é reconhecido por diversos estudiosos, independente de fazerem ou não uma crítica radical ao sistema do capital, como é o caso de Romeiro (2007, p.282):

[...] na agricultura, ao contrário do que ocorre nos demais setores produtivos, os impactos ambientais provocados pelos processos produtivos adotados afetam sua própria base de produção, o ecossistema agrícola. A prática da monocultura em si mesma é uma fonte de desiquilíbrios ambientais cujos efeitos sobre a produtividade agrícola têm que ser enfrentados.

Esse modelo agrícola construído permitiu a manutenção de uma das estruturas agrárias mais arcaicas do mundo com um índice de Gini estacionado em 0,8, ou seja, quase concentração absoluta. Portanto, ainda convivemos com o chamado modelo agroexportador de produção inerente ao desenvolvimento do capitalismo na formação social brasileira, que não eliminou o latifúndio, e historicamente excluiu a classe trabalhadora dos processos decisórios

O outro lado da mesma problemática, portanto, é a existência de milhões de sem terras ou camponeses com pouca terra, que se organizam, mobilizam e lutam pela reforma agrária e por políticas agrícolas e agrárias voltadas para a agricultura familiar e camponesa. No entanto, a luta pela redemocratização da terra no Brasil produz e reproduz sistematicamente desigualdade social e violência no campo. Segundo Mansur (2018) a Comissão Pastoral da Terra (CPT) em 2013 registrou 34 assassinatos, em 2017, esses números cresceram 105\%, chegando a 70 execuções. O levantamento da CPT também chama atenção para o retorno dos massacres, sendo que em 2017, foram registrados quatro, que resultaram em 28 mortes ou $40 \%$ do total daquele ano. Eles aconteceram em Colniza (MT), Vilhena (RO), Pau D`Arco (PA) e Lençóis (BA).

Mansur (2018) mostra que os registros feitos pela CPT desde 1985 apontam a ocorrência de 1.438 casos de conflito no campo que deixaram 1.904 vítimas até 2017 . Destes, apenas 113 foram julgados, o que corresponde a 8\% dos casos. 0 gráfico abaixo ilustra tal realidade, 
Gráfico 1 - Assassinatos no Campo Brasileiro (2013-2017)

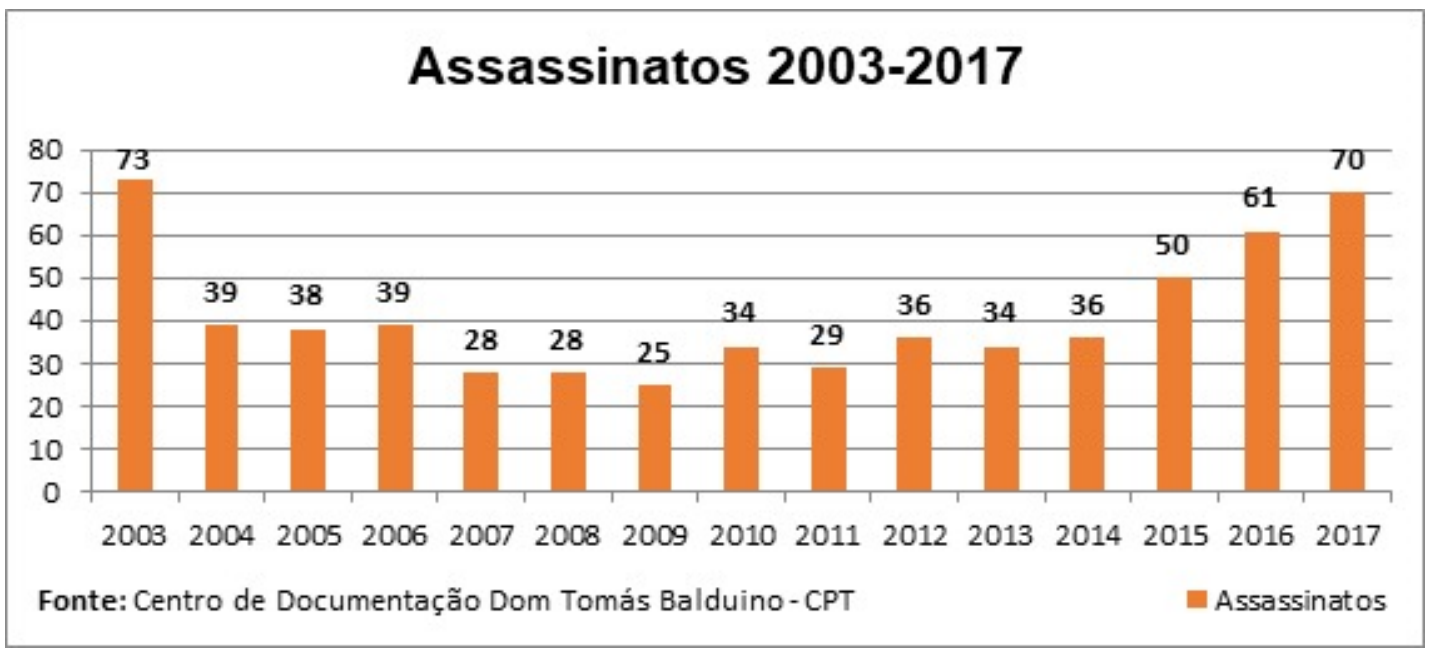

Fonte: Mansur (2018).

Para invisibilizar o conflito, ganhar legitimidade social e receber os aportes financeiros das políticas agrícolas e agrárias, hoje, os grandes capitalistas agrícolas se associam ao capital industrial e financeiro para o desenvolvimento do que convencionam chamar de "agronegócio", modelo de desenvolvimento econômico legitimado pelo Estado Brasileiro que não só produz como reproduz cotidianamente a questão agrária, particularidade da questão social no Brasil.

$\mathrm{Na}$ realidade, burguesia nacional e internacional vão cada vez mais se apropriando das terras brasileiras para garantir ao acesso aos recursos naturais e a biodiversidade, para manter a terra como reserva de valor, ou para desenvolver práticas agrícolas, via de regra, grandes monoculturas cujos produtos são destinados ao mercado externo. Conforme Barbosa (2012, p. 70) destaca:

\begin{abstract}
Os beneficiados pelo agronegócio usam o resultado das exportações $-76,4$ bilhões de dólares em 2010 - para justificar o atual modelo de agricultura brasileira. São incapazes de ver os malefícios de um modelo agrícola que concentra $84,8 \%$ do valor da produção total em apenas $8,1 \%$ do total dos estabelecimentos agrícolas. No outro extremo, há 3,7 milhões de estabelecimentos agrícolas, representando $72,9 \%$ do total, que não conseguem ter uma renda mensal superior a dois salários mínimos. E, dentro desse segmento, há 2 milhões de estabelecimentos com uma produção anual de aproximadamente um salário mínimo. Para estes, a atividade econômica agrícola torna-se totalmente inviável e o meio rural se restringe a ser um espaço de moradia. Os defensores do agronegócio olham para este contingente populacional, cerca de 11,3 milhões de pessoas, como os inevitáveis futuros habitantes das favelas e dos grandes centros urbanos
\end{abstract}

Sant'Ana (2012, 2014) explicita a questão agrária compõe a questão social. Historicamente suas manifestações se apresentaram de diferentes formas: no intenso êxodo 
rural, no desenraizamento e morte de grandes contingentes das populações tradicionais com a invasão das atividades agrícolas sobre seus territórios, na luta e resistência dos trabalhadorxs para permanecer na terra ou para conquista-la por meio da reforma agrária, nos conflitos dos assalariados rurais das diversas atividades agrícolas e em diferentes momentos históricos; também está nos massacres que o capital e Estado promoveram dos diversos povos como indígenas, quilombolas, camponesas, ribeirinhos e muitos outros.

Atualmente a questão agrária continua presente e até de maneira mais alargada, pois seus rebatimentos trazem consequências nefastas para o conjunto da população à medida que o modelo de desenvolvimento econômico calcado no agronegócio tem resultado em padronização alimentar, envenenamento da água e dos alimentos disponíveis para o consumo, nas condições de vida e trabalho dos assalariados rurais, no adoecimento do trabalhador em decorrência do trabalho no meio rural, na migração e no desemprego.

\begin{abstract}
O atual modelo agrícola está voltado fundamentalmente para as atividades do agronegócio que reúne em sua cadeia produtiva capital agrário, industrial e financeiro, nacional e internacional. A agricultura familiar e a camponesa permanecem com menores investimentos e resistindo à pressão do modelo hegemônico que produz tecnologia voltada para a monocultura e inflaciona o mercado de terras, de maneira a dificultar uma reforma agrária ampla e massiva e uma política agrícola de bases agroecológicas. Os rebatimentos desse processo sobre o mundo do trabalho são evidentes: a desertificação do campo em áreas de monocultura, a diminuição dos agricultores familiares e camponeses, a precarização do trabalho assalariado, a concentração dos maiores índices de pobreza em área rural e, o acirramento da luta pela terra (SANT'ANA, 2014, p. 11).
\end{abstract}

A questão agrária necessita ser discutida enquanto particularidade da questão social no processo de formação profissional, assim como precisa estar nas pautas de luta dos profissionais, pois impacta diretamente no cotidiano de trabalho do assistente social, principalmente quando este atua em municípios de pequeno porte cuja base da economia gira em torno da produção agrícola de grande porte.

As resultantes desse modelo agrícola também estarão presentes nos níveis de adoecimento da população devido aos altos índices de contaminação dos alimentos ingeridos diariamente e que possuem uso abusivo de agrotóxicos, ou até mesmo o contato com o veneno durante o processo de trabalho; no acesso restrito a uma alimentação balanceada e popular, já que em diversas regiões do Brasil as terras agricultáveis são majoritariamente voltadas para o monocultivo ou agropecuária em larga escala o que incide na baixa produção e diversidade de gêneros alimentícios, os quais ficam onerosos a classe trabalhadora; no êxodo rural que a desertificação das monoculturas provoca; no 
"endividamento" da classe trabalhadora por meio do sistema creditício de construção de casas populares e etc. Portanto, essas manifestações compõem a questão agrária nos diferentes espaços de trabalho profissional, como uma particularidade da questão social. É evidente que aparecendo mediada por diversas determinações, exige capacitação teórico metodológica para sua apreensão. Daí a importância da direção profissional construída historicamente pelo Serviço Social e de seus aportes teóricos sustentado numa perspectiva crítica e dialética, voltados à apreensão da realidade numa perspectiva de totalidade.

Os assistentes sociais têm como princípio ético-político a: "Opção por um projeto profissional vinculado ao processo de construção de uma nova ordem societária, sem dominação, exploração de classe, etnia e gênero." Nesta direção, a apreensão das particularidades que compõem a questão social que advém do modelo de produção agrária e agrícola é parte da qualificação profissional para uma análise dos determinantes fundamentais que compõem as tensões e lutas de classe vigentes nessa sociabilidade.

Só para ilustrar essa assertiva: na luta por reforma agrária mais de 70 movimentos sociais estão presentes em área rural; muitos deles têm expressão nacional como é caso do Movimento de Trabalhadores Rurais Sem Terra (MST). O Movimento dos atingidos por Barragens (MAB), Movimento dos Pequenos agricultores (MPA), Movimento Nacional de Mulheres Camponesas (MNMC) e outros. Numa sociedade cujo Estado e os meios de comunicação dão visibilidade e apoiam o agronegócio, ocorre a criminalização e a desqualificação daqueles que lutam, especialmente os sujeitos coletivos, pois são eles que estão pensando e construindo novos modelos para a agricultura, com propostas agroecológicas.

Quando o assistente social apreende estes processos que compõem a questão agrária, na efetivação do compromisso estabelecido pela sua profissão, pode no seu trabalho ou em pesquisas dar visibilidades a estas bandeiras de luta e resistência, contribuir com a descriminalização, discutir o direito à alimentação, segurança alimentar e nutricional a partir do debate sobre a questão agrária como propõe Teixeira (2015); trazer a pauta e lutar pela reforma agrária como política pública redistributiva para além do minimalismo das políticas distributivas como as políticas sociais como propõe Masson (2016), e mesmo outras temáticas ambientais e sociais como um componente de seu trabalho socioeducativo e político.

Outra possibilidade histórica que se assenta para além dos espaços institucionalizados da esfera estatal - onde estão a maior parte de profissionais, é a uma 
atuação permanente junto aos movimentos sociais oriundos da classe trabalhadora, pois o Serviço Social é uma profissão que historicamente não só construiu e consolidou seu compromisso profissional junto aos interesses da classe trabalhadora, como também é parte classe trabalhadora.

\section{Considerações Finais}

Partiu-se da reflexão de que o Serviço Social brasileiro teve sua profissionalização perpassada por uma trajetória contraditória inerente ao próprio movimento capital/trabalho, o qual originou o objeto de intervenção profissional do assistente social: a questão social. Discutiu-se o quanto a lei geral de acumulação capitalista, produtora e reprodutora da questão social, é mitigada por meio de políticas públicas que não inferem na estrutura de sociedade atual marcada por profundas desigualdades.

A institucionalização da profissão no Brasil vai se dar numa realidade sócio-histórica determinada pela configuração de capitalismo tardio. Os chamados "agentes sociais" responderam historicamente às demandas impostas atinentes aos interesses de uma elite agrária aliada a um Estado, que historicamente exclui a classe trabalhadora dos processos decisórios.

A partir de referenciais conservadores o Serviço Social cumpre inicialmente as determinações das classes dominantes e do Estado no incipiente processo de industrialização: amenizar os conflitos e as tensões sociais advindos das relações de trabalho e, segue nesse papel sem conflitos internos de monta até o início da década de 1960. Nesse período, influenciado pelo movimento internacional de renovação do Serviço Social latino americano e pela conjuntura interna do país, a profissão inicia o debate e a revisão do seu ethos profissional. Esse processo denominado de Movimento de Reconceituação foi complexo e diverso, especialmente devido a instauração do regime militar em 1964. Mas, foi a partir dele que ocorre a organização e mobilização da categoria profissional e suas entidades, para que no final de década de 1970, a corrente denominada por Netto (2005) de "intenção de ruptura" assumisse a direção do Serviço Social brasileiro. Isto possibilitou a interlocução com um referencial teórico capaz de decifrar as determinações da sociabilidade regida sob a ordem do capital.

A teoria social de Karl Marx permitiu a construção de uma direção crítica, voltada para a defesa da classe trabalhadora e numa perspectiva anticapitalista e emancipatória. A 
essa direção denominamos de PEP é construída diariamente por estudantes, profissionais e por nossas entidades representativas, como uma realidade histórica possível.

No entanto, diante o recrudescimento da questão social, exponenciada na atualidade por uma conjuntura muito adversa, é cada vez mais latente a necessidade dos estudantes e profissionais se atentarem e se comprometerem com este referencial teórico que nos possibilita decodificar a realidade a partir de múltiplas determinações.

Assim, esta reflexão além de provocar a necessidade de aprofundamento teóricocrítico para o entendimento do significado social da profissão, também reclama o entendimento, estudo, e militância acerca de uma das particularidades da questão social na formação social brasileira: a questão agrária.

A questão agrária no Brasil é componente estrutural da sociabilidade brasileira e faz com que a questão social tenha uma dada configuração específica, marcada por profundas desigualdades. A forma como a questão agrária se particulariza no cotidiano profissional nem sempre evidencia seus determinantes. Mas, um país com concentração quase absoluta da terra e cuja produção está organizada a partir dos interesses do capital; que prioriza a produção em larga escala de produtos voltados para a exportação, que utiliza agrotóxicos em larga escala, precariza a força de trabalho, que não realiza Reforma Agrária, evidentemente não pode discutir questão social, desconsiderando a questão agrária.

Os assistentes sociais, comprometidos com os princípios éticos-políticos da profissão, necessitam identificar as refrações da questão social que são resultantes da questão agrária e, com isso poderá realizar um trabalho mais qualificado envolvendo os sujeitos coletivos que discutem a temática, inclusive levando os para fazer o debate no âmbito das políticas sociais, com seus usuários.

Os movimentos sociais organizados pela redemocratização de terras no Brasil, historicamente, travam lutas sociais que questionam o atual modelo de desenvolvimento econômico do Estado brasileiro, calcado no agronegócio. Contribuir com essa luta perpassa o trabalho profissional e vai para além dele: pode ser também uma opção do profissional colocar-se nesta trincheira de organização e resistência de maneira a efetivar uma direção emancipatória em prol de sociedade justa e igualitária. 


\section{Referências}

BARBOSA, Alexandre de Freitas. O Brasil real: a desigualdade para além dos indicadores. São Paulo: Outras Expressões, 2012.

CFESS - CONSELHO FEDERAL DE SERVIÇO SOCIAL. Resolução CFESS n. 273, de 13 de março de 1993. Dispões sobre o Código de Ética do Assistente Social. In: CRESS/SP - 9a Região (Org.). Legislação brasileira para o Serviço Social. 3. ed. São Paulo, 2008.

DINIZ, Tânia Maria Ramos de Godói. Questão urbana e direito a cidade: reflexões sobre o trabalho social na política urbana. Revista Conexões Geraes, Belo Horizonte, v. 3, n. 5, p.6369, sem. 2014.

IAMAMOTO, Marilda Villela. Serviço Social em tempo de capital fetiche: capital financeiro, trabalho e questão social. 3. ed. São Paulo: Cortez, 2008.

IAMAMOTO, Marilda Villela. Serviço social na contemporaneidade. 3. ed. São Paulo: Cortez, 2001.

IAMAMOTO, Marilda Villela; CARVALHO, Raul de. Relações sociais e Serviço Social no Brasil: esboço de uma interpretação histórico-metodológica. 16. ed. São Paulo: Cortez: CELATS, 2014.

MANSUR, Vinícius. Assassinatos no campo subiram 105\% desde 2013, aponta CPT. Disponível em: <https://www.brasildefato.com.br/2018/04/16/assassinatos-no-camposubiram-105-desde-2003-aponta-cpt/>. Acesso em: 2 jul. 2018.

MARINI, Ruy Mauro. Dialética da dependência,1973. In: STÉDILE, João Pedro; TRASPADINI, Roberta (Org.). Ruy Mauro Marini: vida e obra. 2. ed. São Paulo: Expressão Popular, 2011. p. 137-180.

MARX, Karl. O capital: crítica da economia política. 23. ed. Rio de Janeiro: Civilização Brasileira, 2009.

MASSON, Gabriela Abrahão. A Reforma Agrária como política pública de Desenvolvimento: análise a partir dos Assentamentos Rurais "Tereza do Cedro" e "Dandara" no município de Uberaba/MG. 2016. 407 f. Tese (Doutorado em Serviço Social) - Faculdade de Ciências Humanas e Sociais, Universidade Estadual Paulista "Júlio de Mesquita Filho", Franca, 2016.

MOTA, Ana Elizabete Simões da (Org.). O mito da assistência social: ensaios sobre Estado, política e sociedade. 3. ed. São Paulo: Cortez, 2009.

NETTO, José Paulo. Capitalismo monopolista e Serviço Social. 2. ed. São Paulo: Cortez, 1996.

NETTO, José Paulo. Ditadura e serviço social: uma análise do Serviço Social no Brasil pós1964. 8. ed. São Paulo: Cortez, 2005.

NETTO, José Paulo. Estado, política e emancipação humana. In: GARCIA, Carla Cristina; HÚNGARO, Edson Marcelo; DAMASCENO, Luciano Galvão (Org.). Estado, política e emancipação humana: lazer, educação, esporte e saúde como direitos sociais. Santo André: Alpharrabio, 2008. 
NETTO, José Paulo. Projeto ético político do Serviço Social e sua relação com a reforma sanitária: elementos para o Debate. In: BRAVO, Maria Inês. Serviço Social e Saúde: formação e trabalho profissional. São Paulo: OPAS, OMS, Ministério da Saúde, 2006. p. 197-217.

PRADO JÚNIOR, Caio. A questão agrária no Brasil. 5. ed. São Paulo: Brasiliense, 2000.

ROMEIRO, Ademar Ribeiro. Perspectivas para políticas agroambientais. In: RAMOS, Pedro (Org.). Dimensões do agronegócio brasileiro: Políticas, instituições e perspectivas. Brasília: NEAD Estudos, 2007. p. 283-312

SAN'TANA, Raquel Santos. Trabalho bruto no canavial: questão agrária, assistência e Serviço Social. São Paulo: Cortez, 2012.

SAN'TANA, Raquel Santos. Trabalho e desenvolvimento: a realidade rural e a questão social. Serviço Social \& Sociedade, São Paulo, n. 120, p.723-745, out./dez. 2014.

SANTOS, Josiane Soares. Questão social: particularidades no Brasil. São Paulo: Cortez, 2012.

SILVA E SILVA, Maria Ozanira e (Coord.). O Serviço social e o popular. Resgate teórico metodológico do projeto profissional de ruptura. São Paulo: Cortez, 1998.

SILVA, José Fernando da Siqueira da. Serviço social: resistência e emancipação? São Paulo: Cortez, 2010.

STÉDILE, João Pedro. Programa agrário da campanha presidencial do PT - 2002: Programa Vida Digna no campo. In: STEDILE, João Pedro. A questão agrária no Brasil: programas de reforma agrária - 1946-2003. 2. ed. São Paulo: Expressão Popular, 2012. v. 3.

TEIXEIRA, Leile Silvia Cândido. O valor da fome no Brasil: Entre as necessidades humanas e a reprodução do capital. 2015. 253f. Tese (Doutorado em Serviço Social) - Universidade Federal do Rio de Janeiro (UFRJ). Rio de Janeiro, 2015. 